\title{
Hereditary ataxia, presumed to be of the Menzel type, complicated by paranoid psychosis, in a mother and two sons
}

\author{
KENNETH M. G. KEDDIE \\ From Sunnyside Royal Hospital, Montrose
}

The spinocerebellar degenerations are defined (Greenfield, 1954) as a group of progressive diseases characterized by disturbances of the co-ordination of movement, or ataxia, and pathologically by degeneration of those afferent and efferent neuronal systems on which the smooth and efficient regulation of movement depends. The pathological process appears to be a slow or more rapid dying back of the neurones in certain systems from the periphery to the centre with eventual disappearance of the cell body.

Greenfield classifies spinocerebellar degenerations into three types. First, there are the predominantly spinal forms, comprising Friedreich's ataxia and hereditary spastic ataxia. The second group, the spinocerebellar forms, comprise the Menzel type of hereditary ataxia and subacute spinocerebellar degeneration. Thirdly, there are the predominantly cerebellar forms, consisting of the Holmes type of hereditary ataxia, diffuse atrophy of Purkinje cells, olivo-ponto-cerebellar atrophy, and dentato-rubral atrophy. Greenfield had searched the literature from 1891 for cases of hereditary ataxia coming on in adult life. He traced 22 families, in which degeneration of the cerebellum, usually combined with degeneration of related tracts and neuronal systems, had been found. He observed that the lesions described fell, more or less sharply, into one or other of two anatomical groupings, the type described by Menzel (1891) or the type described by Holmes (1907). In the former there is atrophy involving the middle cerebellar peduncles, nuclei pontis, medullary olives, and the cerebellar white matter in that order of constancy. In addition, in most of the reported cases, one or more of the long tracts of the spinal cord-that is, dorsal columns, direct and indirect spinocerebellar tracts, and pyramidal tracts-are degenerated. In the form described by Holmes, the disease falls with greatest severity on the cortex of the superior half of the cerebellum. The pyramidal tracts do not undergo degeneration.
Referring to the mental symptomatology of the hereditary ataxias, Greenfield notes that some degree of dementia may set in late in the disease in longterm cases, of both the Menzel and Holmes type. Usually no definite histological changes are to be found in the cerebral cortex. Bleuler and Walder (1947), in a study of the hereditary ataxias, found an exaggeration of sentimentality and of the influence of emotions on reason, vagueness, and poverty of imagination. Such features did not necessarily occurō in association with evidence of dementia. Ado-艿 lescents suffering from Friedreich's ataxia often $\bar{\Phi}$ show minor intellectual difficulties, a tendency too irritability, and even hallucinations and paranoid ideas (Knoepfel and Macken, 1947).

Greenfield lists 23 patients from the literature suffering from Menzel type of hereditary cerebellafo degeneration. Psychiatric features were noted in only two of these: one was noted to be 'irritable' (Fickler, 1911) and the other showed 'irritability, poor judgement, minor disorientation in time and paranoid trends' (Schut, 1950). No evidence of psychosis was reported in any of the cases.

A middle-aged man was recently admitted to hospital with a severe paranoid psychosis that had been complicated in the latter stages by heavy drinking. He also had generalized ataxia that was shown later to be due to spinocerebellar degenerative disease. Further interest was aroused when it became known that the patient had an elder brother who had been hospitalized in a nearby mental hospital for many years on account of a paranoid psychosis. This brother had developed in recent years disabling widespread ataxia. The mother of these two men died in a mental hospital after suffering for many years from delusions of persecution. Generalized ataxia characterized the last 15 years of her life. As the brothers show signs both of cerebellar dysfunction and bilateral pyramidal tract lesions, it would seem fair to assume that they comprise an example of the Menzel type of hereditary 
cerebellar degeneration. Though clinical details are sparse in the case of the mother, it would appear likely that she too had this type of cerebellar disease. It was considered worth while to record briefly the clinical details of these cases of hereditary ataxia, in view of the unusual association of the disease in all three with a paranoid psychotic illness.

\section{CASE REPORTS}

CASE 1 The mother ( $M$ in family tree) in this family was born in the 1880s, the fifth of a sibship of seven. Her own mother died in childbirth (see Fig. 1). There are no available details of her father. Three of the sibs are still alive and well. The remainder died either in their 60 s or 70 s without any evidence of preceding chronic neurological disease.

She married at the age of 21 , and subsequently had four children, including the two cases recorded later. At the age of 52, seven years after her husband had died, she was admitted to a mental hospital in the West Country. For approximately 10 years before this she had become increasingly paranoid about both her own family and neighbours. She would become extremely irritable at times, and might even resort to throwing things around the room. At the same time she drank beer to excess. Her admission to the mental hospital was precipitated by a suicidal attempt. She remained in hospital until her death at the age of 65. At the time of her hospital admission she had widespread ataxia which became increasingly worse over the years. The year before her death she was noted to be 'partially paralysed' and there was undoubtedly evidence of dementia. Because of physical disabilities she was unable to write. Death was thought to have resulted firstly from 'cardiovascular degeneration' and secondly from 'disseminated sclerosis'. For the reasons discussed later, it is probable that her physical disabilities resulted, in fact, from a chronic neurological disease identical with that which her two sons are suffering from.

CASE 2 (Son I) He was fairly clever at school, left at the age of 14, and spent some years as a shop assistant until he joined the Army in 1939. He married at the age of 24 , and there were two daughters who are both alive and well. He lost his wife from pulmonary tuberculosis at the end of the war. There was some form of mild breakdown while serving overseas. In addition he had dysentry and malaria, the latter on several occasions. By the time he was demobbed, he was already widowed, and he began to spend most of his time drinking heavily. The following year, at the age of 36 , he was admitted to a mental hospital on a reception order. For the three months before this he had become increasingly excited and paranoid. It was reported that he often shouted offensive remarks at night. His next-door neighbour, a most inoffensive woman, was once threatened in the following terms: 'I have a Gurkha knife and it slashes you to the ground, you dirty bitch.' This gross disturbance occurred nightly. He apparently also wrongly entertained the idea that his wife had been unfaithful during his time abroad.

Mentally, on admission, he was noted to be distractable, extremely restless, and disorientated for time and place. There was some clouding of consciousness. Conversation was rapid and irrelevant, and there was poor memory for recent and remote events. He was considered to be auditorily hallucinated and subject to persecutory delusions. He was most noisy and looked neglected. For a few weeks after admission he was considered to be dangerously aggressive. There were no physical abnormalities and haemoglobin, urine analysis, WR, and chest radiograph were normal.

$\mathrm{He}$ was considered to be suffering from paranoid schizophrenia and was given a course of ECT with some benefit to his condition. He has continued to receive different types of medication over the years, but despite

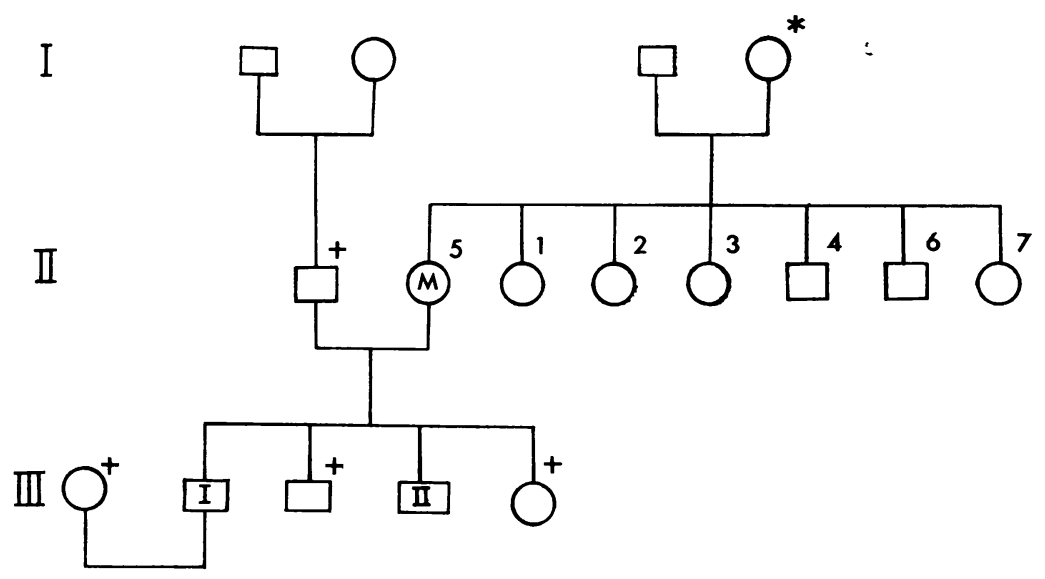

FIG. 1. Family tree. All members represented here are dead, except for the brothers $I$ and II. I and II =clinically diagnosed cases of Menzel type of hereditary ataxia. $M=$ presumed case of Menzel type of hereditary ataxia. $\dagger=$ died of pulmonary tuberculosis. * = died in childbirth. 
this he has never altogether lost his delusions of persecution and he is also thought to have remained auditorily hallucinated much of the time. It is for this reason that he has remained in hospital. At the age of 43 he was noted to have periodic jerky movements of a choreiform nature affecting the limbs. These subsequently stopped, but six years later hesitancy of speech became a definite feature and he exhibited ataxia both in the arms and legs. Dementia started to become apparent at this time. Spastic paraparesis of the lower limbs was noted. There was no nystagmus.

In 1964, when the patient was 53 years of age, the physical examination was repeated. Abnormalities were confined to the central nervous system. The pupils were small and reacted slowly to light and accommodation. There was no nystagmus. Dysarthria, intention tremor of the hands, adiadokokinesis, and an ataxic gait on a wide base were noted. The reflexes were sluggish but symmetrical and the plantar responses extensor. Tone was generally decreased. Power was diminished in all limbs, especially in the legs. The patient's statement that he felt his left arm and leg to be weaker than their counterparts was not confirmed objectively. Sensory functions were unimpaired.

On the same occasion his mental state was reassessed. He was found to be extremely co-operative but became tired easily. There was flattening of mood, and he felt that people were against him but would not give further details of these paranoid ideas. He denied auditory hallucinations but the nursing staff considered that he did hear voices from time to time. He was moderately well informed about current events. He was given some psychological tests and the report was as follows: 'On the Standard Progressive Matrices he scored at approximately the 14th percentile rank. This gives him an approximate IQ of 84. On the "Synonyms" section of the Mill Hill Vocabulary Scale he scored at the 24th Percentile rank-that is, in Grade 4, which is "definitely below average in verbal ability",' The Minnesota Multiphasic Personality Inventory record was a technically invalid one in virtue of an extremely elevated ' $S$ ' score. An EEG and a serum $B_{12}$ estimation were not performed in this case.

CASE 3 (Son II) The paternal grandmother had died at the age of 90 having enjoyed fairly good health till near the end of her life. There are no details of the paternal grandfather. His father had died at the age of 52 from tuberculosis. His mother, case 1, as described above, spent the last 13 years of her life in a mental hospital. His eldest brother, case 2, also described above, is two years his senior and has spent the last 17 years of his life in a mental hospital. The patient's elder brother died from pulmonary tuberculosis as did his young sister. Apart from his mother and his eldest brother there is no other history in the family of heavy drinking, psychosis, or chronic neurological disease.

He is a happily married man of 53 and there are three children, two girls and a boy, all of whom are well. Physical relations with his wife were normal till three months before his first hospital admission in 1963 at which time he became 'oversexed'. He has apparently been impotent since then. His wife describes their marriage as a basically happy one. He has always tended to be a bit moody and a somewhat irritable person and these tendencies were more pronounced in the two years before his first admission. All his married life he has controlled a family business. There was no history of physical or psychiatric illness in the past.

For approximately five years before his admission to hospital he had tended to te suspicious of people in general. In the last 12 months of this period he became extremely paranoid about his wife and believed she was being unfaithful. This delusion became so pronounced that he initiated legal proceedinzs which were subsequently dropped. In the last two years before his admission the family business began to run into debt, mainly on account of his faulty judgement which appeared to stem, in turn, from grandiose and unrealistic thinking. While the business was running down he began to drink spirits very heavily, and he also engaged in an affair.

Eventually his condition deteriorated so much that $\overrightarrow{0}$ admission to hospital under Section 25 of the Mental Health Act was necessary. Mentally he was garrulous and superficially gay. He had delusions of persecution which persisted for a further 10 weeks. There were also delusions of grandeur; he thought he had been admitted to hospital so that doctors could study his 'spectacular brain'. On this occasion physical examination proved to be essentially normal apart from some slurring of speech which was thought to be due to his new dentures. A fu界 blood count, blood urea, liver function tests, WR, urine analysis, chest and skull radiographs, and EEG were al found to be normal. His psychiatric state responded to moderate doses of trifluoperazine (Stelazine) ang benzhexol (Artane) and he was discharged after 12 week $\vec{\varphi}$ in hospital. Twelve months after his discharge he gaine insight into the pathological nature of his previous $\mathbf{s}^{+}$ behaviour. He then decided to leave the running of the family business to his wife.

On one of his visits to the follow-up clinic he complained of vertigo and there was a tendency to veer to the right. A year and a half after his original admission to hospital when he was 51 , he was readmitted on account of the now evident ataxia. There were no abnormal psychiatric features apart from some slowing of the thought processes. On this occasion good rapport was achieved. Physical examination showed the central nervous system to be grossly affected. Dysarthria was marked. Finger-nose and heel-knee tests showed gross inco-ordination on both sides. Adiadokokinesis was marked. Rebound phenomena could be elicited in both arms. Knee jerks were pendular and the plantar responses were equivocal. Clonus of both ankles was elicited. His gait, which was on a wide base, was grossly ataxic, and Romberg's test was positive; he tended to veer to the right. Tone was diminished in the arms but normal in the legs. The left arm and leg were slightly weaker in power than their counterparts. Nystagmus was not a feature, nor was there a static tremor. Sensory functions were intact. The other systems proved to be normal. The serum $\mathbf{B}_{12}$ was normal. The cerebrospinal fluid was found to be normal with regard to colour, pressure, protein level $(30 \mathrm{mg} / 100 \mathrm{ml}$.) and WR. The globulin 
level showed no increase. There was one lymphocyte and $70 \mathrm{RBCs} / \mathrm{c}$. mm, and the Lange test showed no change. After the administration of a tracer dose of radioiodine, both the thyroid uptake at four and 48 hours and the PB $^{131}$ I at 48 hours were within normal limits.

Psychological testing was performed on this occasion and the report was as follows: ' $\mathrm{He}$ was given the Wechsler-Bellevue intelligence scale (form 2) and he obtained a prorated full-scale IQ of 114 . His verbal IQ (109) is high in the "Average" range and his Performance IQ (116) is high in the "Bright Normal" range. There are no clinically significant discrepancies between scores on the different subtests of the scale. These results fail to prove evidence of intellectual impairment. The main features of the Minnesota Multiphasic Personality Inventory were depression and somatic preoccupation. Abstraction ability appeared somewhat impaired on the open-ended and multiple-choice forms of Gorham's proverb test, but no real evidence of concrete thinking, or other psychotic thought disorder, emerged.'

A physician was asked to see the patient and progressive familial spinocerebellar ataxia was diagnosed. The patient was hospitalized for three months, the only medication given being trifluoperazine and benzhexol as before. Eight months after his discharge, these drugs were discontinued. He remained psychiatrically well for only another six months when his paranoid symptoms recurred. Hospitalization was again necessary on this account. At present he is still in hospital and his symptoms are not responding satisfactorily to the present drug regime, which consists of perphenazine and benztropine. The ataxia has continued to get worse.

\section{DISCUSSION}

Concerning the basic lesion in the case of the two brothers, neurological disease other than the hereditary ataxias has to be considered. There was no indication of a relapsing course to either of the illnesses such as is seen in cases of multiple sclerosis. A negative WR excluded GPI and made tabes dorsalis unlikely. Sub-acute combined degeneration was excluded in view of the intact vibration sense and the normal serum $\mathrm{B}^{12}$ level, the latter being assessed only in the younger brother. The clinical pictures could not have resulted from cerebellar tumours, in view of the length of the illnesses. Normal blood-pressure readings and the absence of retinopathy and albuminuria made atheroma of the vertebral arteries unlikely.

The part played by the period of heavy drinking that preceded the paranoid psychosis in each case must be discussed. Alcoholism often runs in families. In chronic alcoholics, certain areas of the brain are particularly liable to undergo degeneration -namely, the cerebral cortex, the cerebellum, particularly the Purkinje cells, the periventricular grey matter, the basal ganglia, the mamillary bodies, and the hypothalmic nuclei. The corpus callosum and the anterior commissure may also suffer (Thompson, 1959). Depending on the site primarily involved, ataxic syndromes may result from these

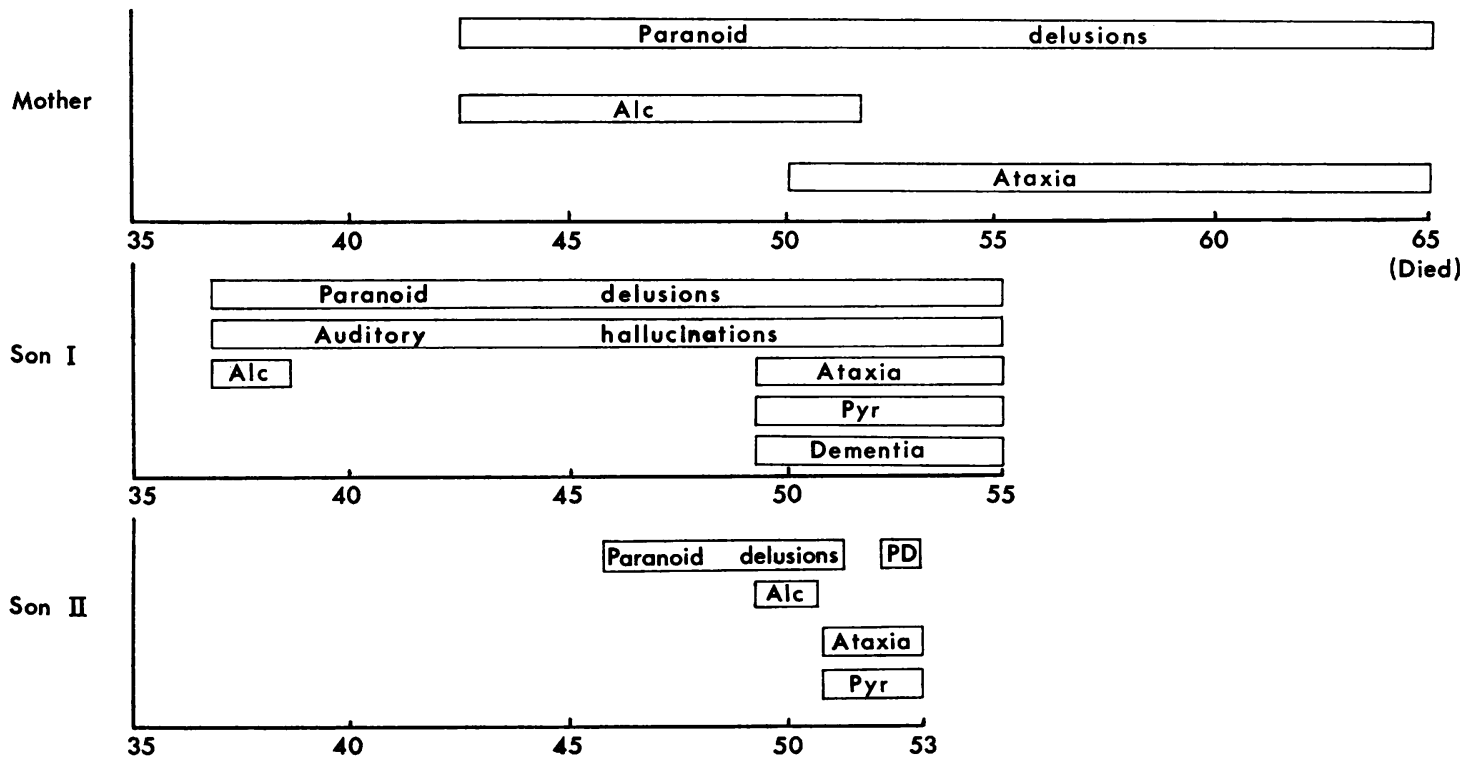

FIG. 2. Temporal relationship of the psychiatric and neurological features in the three cases described. The numbers represent age (in years). Alc = heavy drinking. Pyr = bilateral pyramidal tract lesions. $P D=$ paranoid delusions. 
degenerative processes. Marchiafava's disease is caused by an acute demyelination of the corpus callosum (Mayer-Gross, Slater, and Roth, 1960) and is characterized by confusion, excitement, ataxia, and apraxia. This, however, is a rare disease, and most cases have been described in Italian males who have consumed Italian red wine over long periods of time. Sometimes, on the other hand, alcohol may release a paranoid psychotic reaction in those chronic alcoholics who have basically paranoid personalities (Thompson, 1959). Delusions tend to be less well systematized than in true schizophrenics. In none of the cases described here did the drinking last for many years, and in one case, the younger brother, it went on for only two years. The author therefore feels that alcohol has had no direct part to play in the pathogenesis of the illnesses suffered by the three cases. The early precipitation of hereditary ataxia, as discussed later on, might, however, be postulated. In view of the cerebellar signs, the evidence of bilateral pyramidal tract lesions, and the age of onset (in middle age), the Menzel type of hereditary ataxia would appear to be the likely clinical diagnosis. A necropsy was not performed on the mother, but the ataxia she experienced for 15 years would very likely be of this type also, even although she was diagnosed in her lifetime as a case of 'disseminated sclerosis'.

A search of the literature failed to reveal any report of cases similar to those described in this paper, where a paranoid psychosis had occurred in association with any of the hereditary ataxias supervening in middle life. Certain organic illnesses, do, however, have a well-known tendency to present with paranoid delusions. Both hypothyroidism and sub-acute combined degeneration do this. Multiple sclerosis, which resembles in many ways the hereditary ataxias, can in rare cases appear to cause schizophrenic psychoses, but Pratt (1951) considers that these have been merely precipitated by the condition in individuals previously disposed. Langworthy, Kolb, and Androp (1941) studied 199 cases of multiple sclerosis, of which 16 had been admitted at some time to psychiatric hospitals. These 16 patients showed no characteristic pattern of disturbance. Predominantly depressive features, hypomania, paranoid traits, and grandiose psychoses were all seen. The authors again concluded that the psychopathology is dependent, not upon the type of pathology, but upon the personality make-up. Similarly, in the cases recorded here it is likely that the pathological process responsible for the ataxia caused psychoses of the paranoid variety by acting upon predisposed personalities. The mother and sons appear to have had similar personalities. They were all hypersensitive, moody, and prone to bouts of irritability.
One could surmise that an inherited enzyme defect was responsible in these three cases for both the neurological lesions and the preceding paranoid psychoses, possibly by means of a biochemical disturbance. In view of the fact that none of the mother's six siblings appears to have had an ataxic illness, the responsible gene might be a dominant one of incomplete penetrance. Greenfield (1954) considers that in some cases of hereditary ataxia, extrinsic factors may be responsible for either increasing the liability to the disease or determining its precocious appearance. Alcoholism is one of these postulated factors. Thus the heavy drinking that characterized the early stages of the psychosis in each of the three cases described may have played some part in determining the eventual appearance of the neurological signs.

Paranoid ideation preceded the appearance of ataxia in each of the three cases by a few years (see Fig. 2). The psychosis of the younger of the two sons differed from those experienced by the other two only in its temporary remission by means of anti-psychotic medication.

The strong family history of tuberculosis has been $0 \stackrel{\omega}{N}$ recorded for reasons of interest but it may have no relevance to the syndrome discussed.

\section{SUMMARY}

The case histories of two brothers thought to be suffering from Menzel type of hereditary ataxia, diagnosed clinically, are described in detail. $A$ paranoid psychotic illness affected each of the brothers, before the neurological disturbance became manifest. In the elder brother the psychosis was present for 12 years before the ataxia manifested itself and has persisted, so far, for a further six years. The younger brother was paranoid for only five years before his ataxia became obvious three years ago. The psychosis in this case remitted temporarily under the influence of drugs.

The mother of these two men also had ataxia for the last 15 years of her life. The responsible pathology is likely to have been the same as in the case of her sons. The probability is even greater in view of the fact that she suffered from a paranoid psychosis for the last 23 years of her life.

All the cases showed the common factors of ataxia, paranoid psychosis, and alcoholism. The possible relationship between those syndromes is discussed. The ataxia became first manifest at the ages of 50,49, and 51 in the mother and two sons respectively.

I wish to thank Dr. Max Valentine and Dr. Lindsay Walker for permission to quote from the clinic notes of 
the cases described. I also wish to thank Mr. John Peel (principal psychologist) for the psychometric assessment of the two brothers and Dr. D. Finn for his assistance with the examination of one of the brothers. Dr. Francis Page, consultant physician at Southmead Hospital, Bristol, kindly gave his opinion on the other case.

\section{REFERENCES}

Bleuler, M., and Walder, H. (1947). Die geistigen Störungen bei der hereditären Friedreich'schen Ataxie und ihre Einordnung in die Auffassung von Grundformen seelischen Krankseins. Schweiz. Arch. Neurol. Psychiat., 58, 44-59.

Fickler, A. (1911). Klinische und pathologisch-anatomische Beiträge zu den Erkrankungen des Kleinhirns. Dtsch. Z. Nervenheilk., $41,306-75$.

Greenfield, J. G. (1954). The Spino-Cerebellar Degenerations. Blackwell Scientific Publications, Oxford.
Holmes, G. (1907). A form of familial degeneration of the cerebellum. Brain, 30, 466-489.

Knoepfel, H. K., and Macken, J. (1947). Le syndrome psychoorganique dans les hérédo-ataxies. J. belge Neurol. Psychiat., 47, 314-23.

Langworthy, O. R., Kolb, L. C., and Androp, S. (1941). Disturbances of behaviour in patients with disseminated sclerosis. Amer. J. Psychiat., 98, 243-249.

Mayer-Gross, W., Slater, E., and Roth, M. (1960). Clinical Psychiatry, 2nd ed., p. 468. Cassell, London.

Menzel, P. (1891). Beitrag zur Kenntniss der hereditären Ataxie und Kleinhirnatrophie. Arch. Psychiat. Nervenkr., 22, 160-90.

Pratt, R. T. C. (1951). An investigation of the psychiatric aspects of disseminated sclerosis. J. Neurol. Psychiat., 14, 326-335.

Schut, J. W. (1950). Hereditary ataxia. Clinical study through six generations. Arch. Neurol. Psychiat., 63, 535-568.

Thompson, G. N. (1959). Acute and chronic alcoholic conditions. Pp. 1203-1221 in American Handbonk of Psychiatry, Vol. 2. Edited by S. Arieti. Basic Books, New York. 